\title{
POVO QUIXELÔ: RESISTIR PARA EXISTIR, EXISTIR PARA RESISTIR
}

\author{
Marleide Quixelô
}

RESUMO: O presente artigo é uma pesquisa bibliográfica sobre a presença indígena Quixelô ancestral e as mais diversificadas formas de negações das (r)existências de ascendentes do nosso povo nas contemporaneidades. Busca passar por um breve registro histórico assim como apontar como diferentes instâncias sociais contribuiram(em) para negar de forma estrutural, sistêmica e institucional as (r)existências não só do povo Quixelô, mas também de diversos outros povos indígenas originários do Ceará e do Brasil. Visa discutir como três séculos de (re)colonizações levaram (e levam) para os silenciamentos e marginalizações o povo Quixelô assim como apontar como os direitos e deveres em relação às duplas cidadanias (indígenas/brasileiras) atuais são desconhecidos por parte dos povos, constantemente negados e subtraídos dificultando assim as reafirmações étnicas contemporâneas. Dessa forma, busca pensar como as complexidades em torno dessas temáticas não são demandas somente dos movimentos sociais indígenas, mas inclusive de outros movimentos sociais. As lutas são possíveis hoje pelas apropriações de saberes: legislações indigenistas, ferramentas tecnológicas virtuais, artes/nativismos e autodeclarações individuais para repensar as dificuldades de povos desterrados e "ilhados" em mais de cinco séculos que assolam os nossos povos originários dentro e fora dos territórios (pensando também as problemáticas de indígenas urbanos). Assim possíveis saídas podem ser (re)pensadas nas mais variadas formas descolonizações inclusive dentro dos movimentos sociais indígenas. Num mundo globalizado tem-se que levar em conta que as nossas problemáticas e demandas indígenas/mestiças podem ser compreendidas pelos vieses: histórico-antropológicos, territoriais, educacionais, etc. Mas não só. E hoje essas problemáticas não se resumem apenas a âmbitos locais, mas também a âmbitos regionais, nacionais e globais.

Palavras-chave: Reafirmações étnicas contemporâneas. Movimentos indígenas. Memórias. Descolonizações.

$M O M B Y K Y$ : Ko jehai ha'e peteř jeporeka jehaipyrere ava Quixelo ñemboja ha ijypyre ochuka ave mba'echa heta ñemonguirǐ hape oñemoǐ hekove kuéra ha iñorairõ ñande hente ypy kuéra ko'anga. Ojeporeka ochuka omombe'u ohasa akue harupive ohechauka mba'eichapa umi mombyry mbarete ygua jeikoha omoǐ ipo kuéra nomombe'ui haḡua upecha ombojetu'uve ndaha'ei Quixelo reko kuéra, avei ambue ava Ceará ygua ha Tetã guasu rasil ygua. Upeicha

\footnotetext{
${ }^{1}$ Pertence ao povo indígena Quixelô Cariri (CE/SP) indígenas urbanas/os contemporâneas/os. Possui graduação em Ciências Sociais com bacharel em Antropologia pela UNESP- Universidade Estadual Paulista campus de Marília. Endereço eletrônico: marleidequixelo@gmail.com.
} 
ko mba'apo omombe'u mba'eichapa mbohapy séculos karai rembiapo kyhyje ogueraha mokirǐ ha vaikue jehecha ramo Quixelo kuéra, upéa ojehechauka jejeko ha jejapo arã mokoǐ jehecha ramo ava reko ha ko'angagua hente kuéra ndoikuaa guasuiri, meme upea noñemombe'usei ombojetu'u mombarete teko ko'anga rupi. Ojeporeka ave ojehesamondo ijetu'u verõ ko ava rehegua temática ohechauka ave ambue hente ñemomgu'epe tape oñemombarete haḡua. Ko árape ñeñairõ arandu ñemoǐ porã há'e ikatu: mba'e jekoha ava mba'e tee, tembiporu jeporeka kuaa pya'e, ikatu haḡuaicha hente omombe'u ijehegua ha ojehesa mondo haḡua ambue resa rupi heko kuérare, ava tekoha ygua ha mbairy tetãme oikovare. Ikatu jajehesa mondo ñemohendarã ñemoǐ porã haḡua oñemoǐ akue ikatu ave upéa ava ñemongu'epe. Ko mundo globalizadope tekove ojereraha ñande mba'e oǐ porã yva ha ava/mestiça remikotevē, umiva ikatu ojeikuaa ko'ãva rupi: jehehasa- antropológicos, yvy guasu, educacionais, etc. Ndaha'ei upéa nte. Ko ára rupi ko'ãva ñemohenda'yva noñemombykyi ojeiko harupi nte, oĭ mayma tetãre, tetã michǐre ha tetã guasure.

$\tilde{N} e^{\prime} e \tilde{y}$ ta kuéra: Jekuaave ava ko’angagua. Ava ñemongue. Ñemonguepy. Descolonização.

RESUMEN: El presente artículo es una investigación bibliográfica sobre la presencia indígena Quixelô ancestral y las más diversificadas formas de negaciones de las (r) existencias de ascendientes de nuestro pueblo en las contemporaneidades. Busca pasar por uno breve registro histórico así como apuntar como diferentes instancias sociales contribuiram(yen) para negar de forma estructural, sistêmica e institucional las (r)existências no sólo do pueblo Quixelô, pero también de diversos otros pueblos indígenas originarios en el Ceará y el país Brasil. Visa discutir como tres siglos de (re)colonizaciones levaram (y llevam) para los silenciamentos e marginalizaciones lo pueblo Quixelô así como apuntar como los derechos e deberes en relación as duplas ciudadanías (indígenas/brasileñas) actuales sano desconocidos por parte de los pueblos, constantemente negados y sustraídos, dificultando así las reafirmaciones étnicas contemporáneas. De esta forma, busca pensar cómo las complejidades en torno a esas temáticas no son demandas solamente de los movimientos sociales indígenas, sino incluso en otros movimientos sociales. Las luchas son posibles hoy por las apropiaciones de saberes: legislaciones indigenistas, herramientas tecnológicas virtuales, artes / nativismos y autodeclaraciones individuales para repensar las dificultades de pueblos desterrados e "aislados" en más de cinco siglos que asolan a nuestros pueblos originarios dentro y fuera de los territorios (pensando también las problemáticas de indígenas urbanos). Así las posibles salidas pueden ser (re) pensadas en las más variadas formas descolonizaciones incluso dentro de los movimientos sociales indígenas. En un mundo globalizado se tiene que tener en cuenta que nuestras problemáticas y demandas indígenas/mestizas pueden ser comprendidas por los sesgos: históricos-antropológicos, territoriales, educativos, etc. Pero no sólo. Y hoy esas problemáticas no se resumen sólo a ámbitos locales, sino también a ámbitos regionales, nacionales y globales.

Palabras Clave: Reafirmaciones étnicas contemporáneas. Movimientos indígenas. Memorias. Descolonizaciones.

ABSTRACT: This article is a bibliographical research about the indigenous presence Quixelô ancestral and the most diversified forms of negations of the (r) existence of our people 's ascendants in contemporary times. It seeks to go through a brief historical record as well as to point out how different social instances contributed to deny in a structural, systemic and institutional way the (r) existences not only of the Quixelô people, but also of several other indigenous peoples originating in Ceará and Brazil. It aims to discuss how three centuries of (re) colonization have led (and lead) to the silencing and marginalization of the Quixelô 
people, as well as to point out how the rights and duties of current (Indigenous/Brazilian) dual citizenship are unknown denied and subtracted, thus hindering contemporary ethnic reaffirmation. In this way, it seeks to think how the complexities around these themes are not only demanded by indigenous social movements, but also in other social movements. Struggles are possible today by the appropriation of knowledge: indigenous legislations, virtual technological tools, arts / nativisms and individual self-declarations to rethink the difficulties of exiled and "islanded" peoples in more than five centuries that devastate our native peoples inside and outside the territories (also thinking about urban indigenous problems). Thus possible outlets can be (re) thought in the most varied forms of decolonization, even within the indigenous social movements. In a globalized world one has to take into account that our indigenous/ cross-cultural problems and demands can be understood by biases: historical-anthropological, territorial, educational, etc. But not only. And today these problems are not only limited to local scopes but also to regional, national and global scopes.

Keywords: Contemporary ethnic reassertions. Indigenous movements. Memories. Decolonizations.

\section{Introdução: Um breve histórico}

As nossas histórias imemoriais indígenas dentre elas: as histórias e memórias do povo indígena Quixelô e dos cerca de mil e quinhentos povos indígenas do/no Brasil antes da chegado dos povos colonizadores, segundo a coletânea do (CIMI, 2001) não começam em 1500. As nossas histórias são milenares (milhões de anos), portanto, anteriores a tudo e a todas/os. O povo indígena Quixelô é originário do sertão centro-sul de onde hoje denominam Ceará. Dos quarenta e dois povos indígenas originários dessa região apenas quatorze tem o seus reconhecimentos étnicos garantidos nas contemporaneidades. Pontuamos alguns períodos históricos para situar o povo Quixelô ancestral (e atual) em busca de compreender os enfrentamentos das nossas invisibilidades, problemáticas (indígenas/brasileiras/transnacionais) e as dificuldades de situar nossas demandas nativas/mestiças nas contemporaneidades.

\subsection{Período colonial (1500-1822) - 322 anos}

Onde está o povo Quixelô na história? Nosso povo começou a ser colonizado por volta de 1700, portanto, tivemos quase 200 anos de relativa liberdade antes dos povos colonizadores avançarem sobre nossos territórios, enquanto outros povos indígenas principalmente os da costa do litoral brasileiro já estavam sofrendo (ou contribuindo) com as colonizações como os povos: Tupiniquins, Tupinambás, Tamoios, etc. Por volta de 1700 nosso povo e mais outros povos dos sertões do Ceará começam a sofrer com os impactos das colonizações. Lutamos junto com outros povos nativos na chamada "Guerra dos Bárbaros" 
como ficou conhecida a maior resistência dos povos indígenas do Nordeste. Se um dos principais diferenciadores das culturas dos povos são os costumes e as línguas, podemos relembrar que a nossa língua Kariri foi proibida e os nossos costumes retirados por agentes colonizadores religiosos, militares e civis por isso perdeu-se grande parte da nossa cultura ao longo de séculos. Em 1758 marquês de Pombal proíbe de vez o uso das línguas indígenas e exige o uso do português como língua oficial. Segundo Edileusa Quixelô, nosso povo se encontra hoje onde chamam municípios de Quixelô, Iguatu e Acopiara além de diversas outras cidades brasileiras (NASCIMENTO, Quixelô, 2009, p. 15).

\subsection{Período da monarquia imperial (1822-1889) - 67 anos}

Dois golpes contra os 42 povos indígenas do Ceará que afetam até os dias de hoje os povos dos sertões (dentre eles nosso povo Quixelô).

Em 1850 D. Pedro II decreta a "Lei de Terras" um duro golpe do governo da monarquia com relação aos direitos territoriais dos nossos povos indígenas onde nossas terras passam a ser distribuídas aos colonos. Portanto, quem tinha dinheiro vira proprietário quem não tinha (que é o caso dos nossos povos nativos) eram expropriados, ou seja, ficam e viram sem terras. Como pode terras milenares não ser mais nossas?

Em 1863 o Relatório Provincial de José Bento da Cunha decreta a "Extinção dos indígenas do Ceará" outro golpe contra os nossos povos indígenas, pois retiram a partir daí as nossas identidades étnicas (povo a que pertencemos) como se não existíssemos mais (ANTUNES, 2012, p. 10), ficando assim, mais fácil entregar os nossos territórios a mãos alheias e acabar com as nossas (re)-existências cotidianas. Em 14 de maio de 2012 a deputada Rachel Marques (PT) coordenou junto com alguns povos indígenas do Ceará uma audiência pública na Assembleia Legislativa desse estado como ato simbólico para reparar e reconhecer o erro desse período dito "histórico". Esse momento foi reforçado em 9 de abril de 2015 com a audiência pública solicitada pelo deputado estadual Renato Roseno (PSOL) para debater os direitos dos povos indígenas do Ceará nas contemporaneidades.

\subsection{Período da república velha (1889-1930) - 41 anos}

As políticas indigenistas no país continuam com o viés assimilacionista e integracionista, ou seja, forçar os povos indígenas a seguirem valores, culturas e modelos de vida que não os próprios dos nossos povos. Cria-se nesse período o SPI (Serviço de Proteção aos Índios) em 1910. Onde está o povo Quixelô nisso tudo? Resistindo como sempre, porém com outras roupagens: como agricultoras/es, camponesa(e)s, sem-terras e outras ocupações 
(nas áreas rurais). Como pedreiras/os, domésticas/os e outras profissões (nas cidades). Passamos por muitas mudanças, pois todos os povos são dinâmicos e não congelados no tempo, mas ainda se mantém nos imaginários sociais que os povos indígenas são povos sem história, portanto congelados no fundo do baú da história brasileira (RABESCO, 2014, p.51) e do tempo. As questões são mais profundas e muitas dessas mudanças não fomos nós (e ancestrais) que escolhemos, mas sim fomos (e somos) obrigadas/os a seguir para sobreviver. A história colonizadora pouco ou nada volta os olhares para as complexas dinâmicas e os processos de inserções dos nossos povos nativos contemporâneos ao longo da história brasileira. Contribui assim para construir e incutir imaginários que alimentam que só existem indígenas na Amazônia ou que apenas esses são legítimos. Complexo, não?

\subsection{Período do estado novo/Abertura política (1930-1964) - 34 anos}

Em plena ditadura de Getúlio Vargas (1937-1945) cria-se o "Dia do Índio" em 1943, única data em que alguns setores da sociedade brasileira lembram os povos indígenas mesmo com as profundas lacunas que ela traz. Adesão do encontro ocorrido em 19 de abril de 1940 pelas lideranças indígenas do Continente Americano realizado no México. O Brasil não aderiu imediatamente. Apresentou sua adesão três anos depois com o apoio do militar/sertanista (e também mestiço Bororo/Terena/Guará): Marechal Rondon. As políticas integracionistas prosseguem mesmo com o caráter ambíguo de alguns defensores indigenistas como: Rondon (1865-1958) e os Irmãos Villas-Boas Leonardo (1918-1961), Cláudio (1916-1998) e Orlando (1914-2002) que ajudam a criar o Parque Nacional do Xingu. E onde está o povo Quixelô nisso tudo? Interagindo, migrando, emigrando ou permanecendo nos territórios ancestrais sob os efeitos das muitas políticas assimilacionistas/integracionistas seculares (por séculos) que (n)os denominam por: brasileira(o)s, pardas/os, mestiças/os, etc, (em contextos censitários). Sertanejas(o)s, nordestina(o)s, sem-terras, caboclas/os, cafusas/os, etc, (nas áreas rurais). Ou pobres, classes trabalhadoras, grupos populares, faveladas/os, etc, (nas cidades). Em regiões nacionais ou internacionais.

\subsection{Período da ditadura (1964-1985) -21 anos}

Períodos sombrios continuam para os povos indígenas como podem ser vistos no Relatório Figueiredo (Marins, 2014). Alguns avanços se fazem presentes nesse período: a criação da Fundação Nacional do Índio (FUNAI) em 1967, extinto SPI (Serviço de Proteção aos Índios) criado em 1910 e o Estatuto do Índio em 1973. Período também em que os movimentos indígenas no Brasil se fortalecem para falar sobre suas problemáticas e 
demandas. E onde está o povo Quixelô nisso tudo? Resistindo mesmo com poucos registros históricos, migrando, convivendo, se misturando com outros povos e contribuindo com todos os setores sociais tantos rurais, quanto urbanos e metropolitanos. Porém subtraídos nas “indigenidades apagadas" pelas violências estruturais, sistêmicas e institucionais históricas seculares que estão até hoje incutidos dentro e fora de nós. São perpetuados por diversos setores sociais hostis às nossas presenças contemporâneas (institucionais, patrimoniais, educacionais, de valores simbólicos etnogenocidas (genocídios dos primeiros povos), etc). As usurpações são cotidianas e perpetradas tanto em âmbitos locais, quanto regionais, nacionais e globais. Não é porque a historiografia dita "oficial” diz que não existimos que realmente não estamos presentes nas mais diversas realidades históricas brasileiras (ANTUNES, 2012, p. 10).

\subsection{Período democrático até as contemporaneidades (1985-2018) - 33 anos}

Grandes vitórias se conquistam para os povos indígenas com a Constituição Federal de 1988, pois até que enfim alguns povos originários participam de fato e com suas vozes de espaços que se abrem para a(s) democracia(s), conquistando maiores visibilidades sociais e na Constituição brasileira. Os movimentos indígenas no Ceará começam a ganhar forças e a se organizarem nos anos 90 onde vários povos passam a reivindicar suas (re)-existências: Jenipapos, kanindés, Kariris, Tapebas, Tabajaras, etc. Sem territórios, educações e saúdes diferenciadas, etc; como um povo pode (re)-existir?

Em relação às saúdes e educações indígenas diferenciadas existem também diversas legislações brasileiras algumas delas acessíveis na coletânea indigenista (2008).

Outra grande conquista é a Convenção da OIT - Organização Internacional do Trabalho sobre Povos Indígenas e Tribais (2004), uma das poucas legislações que reconhecem as nossas presenças nas contemporaneidades, portanto, reconhecendo que somos também partes atuantes e integrantes das modernidades coloniais ocidentais assim como somos ascendentes de povos milenares. E por fim a Declaração das Nações Unidas sobre os Direitos dos Povos Indígenas (2007) que reconhece as mazelas deixadas por mais de 500 anos de (re)colonizações no Brasil e diante de outros povos do mundo. E onde está o povo indígena (e mestiço indígena) Quixelô? A gente responde... estamos aqui: consumindo, produzindo, intercambiando, (res)significando, reafirmando, lutando, migrando, retornando, interagindo, etc. Com outras cores, outras ferramentas, em outros territórios,... Nas aldeias, áreas rurais, nas periferias e centros das cidades, em diversas cidades brasileiras ou internacionais!!! 
Muitas/os pesquisadoras/es voltam seus estudos para problemáticas de indígenas do Nordeste como: Luciano Baniwa (2006), Oliveira (1998; 1999), Nascimento Quixelô (2001; 2009) e mais recentemente para o nosso povo Quixelô: Nascimento Quixelô $(2001 ; 2009$; 2015) e Macedo Quixelô, (2016) dentre muitas/os outras/os.

\section{Povo milenar Quixelô nas contemporaneidades}

Como podemos observar os nossos povos dos sertões do Ceará (Siará) - povos milenares -, dentre eles, o nosso povo Quixelô tem cerca de trezentos e dezoito (1700-2018) anos de contatos e interações com os povos estrangeiros. Podemos elencar algumas problemáticas que nos atingem hoje (e atingirão as gerações vindouras), além das dificuldades de (re)afirmações étnicas Quixelô (e de outros povos) nas contemporaneidades. O nosso povo possui cerca de:

1) 318 anos (1700-2018) de colonizações e (re)colonizações que prosseguem até os dias atuais (NASCIMENTO; QUIXELÔ, 2001, 2009), (QUIXELÔ, 2015). Nossas problemáticas e demandas, portanto, são de âmbitos: locais, regionais, nacionais e globais.

2) 260 anos (1758-2018) de negações das nossas línguas nativas pelas políticas anti-indígenas do período colonial com marquês de Pombal decretando a proibição oficial das nossas línguas indígenas (GARCIA, 2007, p. 24). Portanto, a proibição também da nossa língua Kariri do tronco linguístico Macro-Jê. Para se ter uma ideia dos efeitos dessa política dentro do Nordeste hoje apenas o povo Fulni-ô (PE) é bilíngue (fala o seu idioma nativo e português) e conseguiu preservar a sua língua: o Yatê.

3) 168 anos (1850-2018) de negações dos nossos territórios sagrados (NASCIMENTO QUIXELÔ, 2009, p. 38). Portanto, o que conhecemos hoje por municípios de Quixelô, Iguatu, Acopiara e etc; são territórios sagrados do nosso povo Quixelô. Essas e outras cidades ou ditos municípios foram sobrepostos aos territórios indígenas dos povos: Quixelô, Icó, Inhamum, Jucá, Quixexeu, etc, (NIMUENDAJU, 1981). E hoje, se têm que, no mínimo, reconhecer as presenças contemporâneas de ascendentes e mestiças/os indígenas (Segato, 2012), estejam elas/es como e onde estirem: nas áreas rurais, cidades, misturadas/os ou não, dentro ou fora desses territórios.

4) 155 anos (1863-2018) de negações das nossas (re)-existências e identidade étnica Quixelô. Além do nosso povo, existem as negações de outros parentes (povos) como: Inhamum, Jucá, Icó, Pacajus, etc, (ANTUNES, 2012, p.11). Ou seja, em cerca de duas gerações arrasaram(sam) os povos nativos e silenciam ascendentes desses povos de diversas maneiras até as contemporaneidades. 
A relativa e recente abertura democrática (1985-2018) nos dá certa liberdade de reflexão apesar dos conservadorismos de governos tanto de direita quanto de esquerda em relação às políticas públicas direcionadas aos nossos povos nativos (e ascendentes dos mesmos) nas contemporaneidades. O mais viável seriam os próprios povos indígenas (e ascendentes) pensarem em suas multidimensionais lutas coletivas e individuais com formulações de políticas públicas e reparatórias sobre suas histórias e memórias, com a participação também de pessoas não-indígenas mais compromissadas e esclarecidas sobre as demandas concretas dos nossos povos hoje. As questões são que mais de 500 anos de (re)colonizações deixaram (e deixam) marcas profundas em ascendentes indígenas que nascem e crescem dentro ou fora dos seus contextos culturais ancestrais ou diversos (pensando também nas problemáticas de indígenas urbanas/os) (NASCIMENTO QUIXELÔ, 2009, p.121) e talvez nunca se reconhecerão como tal, portanto, são muitas complexidades para serem (re)pensadas dentro das múltiplas diversidades étnicas nativas e estrangeiras que formam e compõem o(s) Brasil(is).

\section{Quixelo: povo uno (origem comum) e diverso (muitas origens)}

Muitos podem afirmar que não existem mais povos indígenas no Ceará ou mesmo em Quixelô, Iguatu, Acopiara, etc. Mas alguns povos já demonstraram que unidos podem sim se organizar, conquistar e saber sobre seus direitos e deveres indígenas usurpados (roubados). Sim, até saber sobre os nossos direitos e deveres indígenas nos retiram principalmente se estiver em contextos "(trans)localizados" (áreas rurais/urbanas dentro ou fora do Nordeste e do Brasil).

Podemos ter como exemplo os povos: Tremembé, Tapeba, Pitaguari, Jenipapo, Kanindé, etc; povos indígenas do Ceará que se organizaram e tem hoje muitas conquistas como: escolas e saúdes indígenas diferenciadas, parcerias e aplicações de projetos sociais, políticas públicas e culturais específicas, assessorias jurídicas, tombamentos/proteções de acervos patrimoniais, valorizações das memórias, repatriações museológicas, museus geridos em parcerias com as/os indígenas, etc.

Pesquisas feitas com os povos indígenas do Nordeste apontam que grande parte dos povos indígenas do Nordeste são hoje misturados (mestiços), como demonstram os estudos (OLIVEIRA, 1998; 1999), pois estamos a mais de 500 anos ou 300 anos (como é o caso do povo Quixelô) em contatos com outros povos: milenarmente com nativos (indígenas) e secularmente com estrangeiros (africanos, europeus, asiáticos, etc). Não vivemos em bolhas isoladas e sim em contatos e intercâmbios com diversos outros povos, portanto, as misturas 
são inevitáveis. Por isso, estamos atualmente com diversas cores: indígenas, negras/os, brancas/os, caboclas/os, cafuzas/os, mestiças/os multi(nativas/os/estrangeiras/os), etc. O problema é que o "mito da democracia racial" é uma ilusão prática e o utilizam para retirar a nossa primeira origem: Quixelô. Assim, contribuem para melhor nos "abrasileirar" ou nos "embranquecer" e negar as nossas (re)-existências contemporâneas inclusive mestiças (SEGATO, 2012, p.115). Dessa forma, denominam-nos por nomes como: brasileiras/os; mestiças/os, pardas/os, etc, (em contextos censitários ou de registros civis). Nordestinas/os, cearenses, camponesas/es, sem-terras, etc, (nas áreas rurais). E faveladas/os, pobres, classes trabalhadoras, extratos/grupos populares, etc, (nas periferias/centros das cidades). Nunca: Quixelô seja lá de qual cor.

Pensando nesse sentido, podemos refletir como o povo japonês não deixa de ser japonês porque pisou no Brasil e se misturou com outros povos. Todo mundo reconhece as presenças nipo-brasileiras (japonesas) mesmo que misturadas e as valorizam enquanto presenças contemporâneas com festividades específicas, bairros/restaurantes diferenciados, duplas cidadanias, etc. Todo mundo reconhece as presenças teuto-brasileiras (alemãs/es); as presenças ítalo-brasileiras (italianas/os), as presenças afro-brasileiras (africanas/os), as presenças luso-brasileiras (portuguesas/es), as presenças anglo-brasileiras (inglesas/es), hispano-brasileiras (espanholas/óis), etc.

Porque não reconhecem as presenças Quixelô-brasileiras? Tremembé-brasileiras? Kaingang-brasileiras? Guarani-brasileiras? Por que não? Por que somente: "brasileiras/os"? A quem interessa nos eliminar (povos secularmente negados) das histórias e contemporaneidades?

Os problemas que nos atingem hoje e talvez por isso as dificuldades de organizações dos nossos povos dos sertões do Ceará são problemáticas de âmbitos: locais, regionais, nacionais e globais. Se nós estamos pisando em solo brasileiro e esse território inteiro é dos povos indígenas brasileiros, somos então primeiro esses povos depois os outros povos (estrangeiros). Temos assim que reconhecer as nossas primeiras matrizes e depois as outras que também nos constitui. O que geralmente não acontece.

\section{Quixelô: povo de simplicidades e complexidades}

Apesar de pertencermos a uma mesma origem comum seja de nascença (mãe ou pai); aderência (adesão ao grupo (povo) Quixelô) ou transcendência (convivências que nos respeitam/reconhecem as nossas resistências), temos muito que (re)aprender sobre nossas próprias histórias/memórias. Apesar de algumas pessoas manterem nos hábitos e costumes as 
simplicidades das nossas heranças ancestrais, ainda enfrentamos (e enfrentaremos) muitas problemáticas complexas em nossos cotidianos. Heranças das políticas assimilacionistas e integracionistas seculares se arrastam ao longo dos tempos em nossos territórios (dentro e fora deles) e nos atingem até os dias de hoje. Podemos pontuar assim muitos desafios complexos dentro das ditas modernidades coloniais contemporâneas que os nossos povos enfrentam (do Ceará, Nordeste e Brasil) como:

1) Não nos ensinam sobre a(s) nossa(s) história(s) e memórias indígena(s) nos currículos ditos "oficiais" do ensino fundamental e médio, seja nas escolas rurais ou urbanas (públicas/particulares) com exceções dos esforços pessoais de algumas/uns educadoras/es e professoras/es locais ou de outras regiões, (apesar da existência da Lei 11645/08 que torna obrigatória as histórias dos povos indígenas e africanos em escolas indígenas e não-indígenas (com muitas presenças indígenas negadas) (NASCIMENTO QUIXELÔ, 2009). Podemos citar um pequeno avanço com Adail (QUIXELÔ, 2015) (educador e também defensor do nosso patrimônio histórico, artístico, natural e cultural) e outras/os tantas/os parentes que conseguiram em 2013 promover a - 1 Gincana Indígena Quixelô - o que teria de ser um trabalho constante e permanente.

Sem políticas públicas indígenas e indigenistas permanentes, como as nossas crianças e jovens vão crescer e se orgulhar de ter as origens comuns (e diversas) Quixelô? Onde ficam as autoestimas para se reconhecerem indígenas (e mestiças/os indígenas) quando nada as suas (e nossas) voltas, (nem programas ou livros didáticos) as (ou nos) valorizam como são e estão (somos e estamos) nas contemporaneidades?

2) Não estamos presentes (porém tentando virtualmente), nos movimentos indígenas organizados do Ceará e Brasil por nos afetar cotidianamente as muitas formas de silenciamentos e negações estruturais, sistêmicas e institucionais seculares que partem tanto de órgãos federais/estaduais/municipais como de (escolas, igrejas, propagandas, redes televisivas/radiofônicas, movimentos sociais, universidades, etc); quanto de outros órgãos de âmbitos regionais/nacionais/globais. De negações em âmbitos locais que alimentam imaginários sociais do nosso povo relegado ao passado negando (ou confirmando negativamente em contextos políticos) (NASCIMENTO QUIXELÔ, 2009, p.12), nossas presenças reais contemporâneas; de colonialismos internalizados (nós mesmos nos desprezarmos) e/ou mesmo as "ignorâncias de si”, ou seja, de uma geração para outra não se saber ou se interessar pela origem étnica, por dificuldades de organizações do nosso povo em âmbito local, por falta de esclarecimentos de pessoas instruídas e remuneradas para nos 
ajudar, defender ou se esclarecer sobre os processos históricos e contextos culturais seculares de apagamentos e negações das nossas histórias e memórias como o órgão indigenista federal (FUNAI) e os difíceis processos de reetinização (reafirmações étnicas atuais).

Ainda há setores que tem responsabilidades sobre os nossos povos, mas se fazem ignorantes (ou não tem uma preparação para lidar com nossas complexas realidades contemporâneas) diante de nossas memórias e histórias inclusive nos dias atuais como (estados, prefeituras, órgãos federais, movimentos sociais, etc), que mudam de configurações de uma gestão política para outra. Por isso as mazelas ditas civilizatórias (ignorâncias de si, dispersões, drogadições, prostituições forçadas, etc), continuarão atingir as outras gerações Quixelô vindouras se uma organização do nosso povo não acontecer mesmo que em longo prazo. Nesse sentido, as ferramentas tecnológicas virtuais ainda são no momento as nossas únicas e possíveis formas de lutas/contatos; de apropriações de saberes em relação às nossas próprias histórias e memórias, sobre as políticas indigenistas vigentes (pois não nos ensinam sobre as nossas origens nas escolas ditas oficiais urbanas/rurais brasileiras quanto mais sobre essas legislações) e as lutas em duas (ou mais) dimensões e direções pelas duplas (ou múltiplas) cidadanias (indígenas/brasileiras/transnacionais). As autodeclarações, artes/nativismos e outros meios de lutas são mecanismos de mobilizações ou de informações sobre como materializar, ressignificar, participar, contribuir ou conhecer melhor os movimentos indígenas do(s) Ceará(s), Brasil(is) e do mundo em suas lutas coletivas ou individuais.

Adail Quixelô conseguiu organizar virtualmente o MINK - Movimento Indígena Kixelô - (MACEDO QUIXELÔ, 2015, p.1) (e acrescentaria das Mesticidades Indígenas Kixelô), mas ainda faltam maiores esclarecimentos/envolvimentos do nosso povo; apoios institucionais locais e (trans)locais, assessorias jurídicas, se municiar com maiores informações sobre as existências (garantias) de direitos e deveres indígenas em leis vigentes contemporâneas e de como organizar o nosso povo localmente (ou mesmo a distancia) em participações e aproximações com outros povos já (re)organizados do Ceará e Brasil. Além disso, existe o Casarão da Memória Viva do Povo Quixelô administrado por José Mácio Quixelô e integra em seus recintos um museu com acervos que testemunha e registra a história e memória do nosso povo mas possui fragilidades institucionais nas garantias do espaço e nas defesas do nosso patrimônio, por isso, as importâncias das aproximações com outros movimentos indígenas para aprender como buscar parcerias nas garantias desses acervos com: tombamentos e registros desse patrimônio como testemunha viva das (r)- 
existências do nosso povo neste lugar e como bem comum do nosso povo Quixelô, patrimônio brasileiro e da humanidade.

3) Os municípios de Quixelô, Iguatu, Acopiara, etc; o estado do Ceará, o Brasil e planeta terra tem que reconhecer as nossas contemporaneidades e os múltiplos efeitos - em nós - das usurpações (roubos) institucionais seculares e cotidianos de nossas: culturas, línguas, territórios, memórias, patrimônios, identidades étnicas, espiritualidades, etc. 300 anos (três séculos) não é 3 dias!!!

4) (Re)-existem indígenas Quixelôs e mestiças/os indígenas Quixelô (SEGATO, 2012), vivendo tanto no Ceará quanto em diversas outras cidades/bairros de São Paulo, Paraná, Tocantins, Maranhão, Pará, Amazônia, Amapá, Santa Catarina, Mato Grosso do Sul, etc. Portanto, as nossas cidadanias indígenas estão "(trans)localizadas” e (des)territorializadas o que indica que cada município e estado tem que reconhecer essas presenças com políticas públicas diferenciadas, reconhecendo nossas contribuições contemporâneas seja lá como ou onde estivermos (QUIXELÔ, 2016, p.7). Dessa forma, nos tornamos "ilhas" (pequenos grupos étnicos ou indivíduos étnicos) em meio a mares de misturas de povos nativos e estrangeiros vivendo em conglomerados urbanos e humanos (cidades) ou áreas rurais dentro ou fora dos nossos territórios.

5) Somos Quixelô em qualquer lugar. Seja vivendo no Brasil ou vivendo em outros países não deixamos de ser Quixelô-brasileiras/os, portanto, as nossas presenças tem que ser consideradas pelas perspectivas: pan-indígenas, que são multi- estrangeiras, trans-local (aldeias/áreas rurais/urbanas), trans-regional, trans-nacional e trans-globalmente), como também, interétnicas e mestiças (SEGATO, 2012) e todas elas precisam ser contempladas. Mesmo enfrentando todas essas complexidades e seja lá onde ou como estivermos: continuamos as ser Quixelôs!!!

6) As dificuldades de enfrentamentos nas reafirmações étnicas pelas políticas indigenistas assimilacionistas e integracionistas secularmente impostas.

Fazemos parte, contribuímos com as mais diversas áreas sociais, ajudamos a produzir tecnologias ou modernidades e as utilizamos no nosso dia-a-dia. Não somos povos isolados em "bolhas" (dançando a dança da chuva ou fazendo uh uh uh) como alimentam muitos imaginários sociais. Estamos milenarmente em contato com outros povos nativos e a mais de 300 anos (três séculos) em contatos interétnicos com outros povos (estrangeiros), portanto, fazemos trocas, produzimos tecnologias e contribuindo com a sociedade dita ocidental moderna colonial como qualquer outro povo do planeta. Estamos nas fábricas, escolas, 
hospitais, etc, (cidades). Nos sítios, fazendas, etc, (áreas rurais/aldeias). Andamos de carro, moto, ônibus, patins, skate, bicicleta, carroça, caminhão, submarino, canoa, jangada, navio, prancha de surf, avião, aeronave, foguete, paraquedas, a pé, de carona, carroça, jumento, etc. Somos catadoras/es de lixo, garis, pedreiras/os, vendedoras/es, professoras/es, comerciantes, empresárias/os, etc. E nem por isso deixamos de ser Quixelô!

7) As dificuldades de quebrar imaginários impostos pela educações monoculturais colonialistas e dos reconhecimentos das nossas contemporaneidades.

Gostamos dos mais diferentes estilos musicais (rock, samba, rap, forró, etc), e participamos dos mais diversos setores sociais: religiosos, profissionais, culturais e movimentos sociais. Vivendo em aldeias, áreas rurais ou cidades (trans)nacionais: com ou sem cocar; com ou sem roupa, rural ou urbano, na pobreza ou na riqueza, com ou sem partido, com ou sem estudos, com ou sem religião, misturadas/os ou não, com ou sem time de futebol, usando tecnologia ou não, na moda ou não, politizadas/os ou não, hetero/homossexuais, mono/pluriparentais, LGBT’SIQs (Lésbicas, Gays, Travestis, Transexuais, Transgêneros, Simpatizantes, Intersexuais, Queers (esquisita/os), etc), solteiras/os, casadas/os, viúvas/os, disquitadas/os, ficantes, crush, encalhadas/os ou querendo beijar muuito, fazendo parte ou não das modernidades coloniais ou descoloniais, podemos ressignificar nas contemporaneidades: os nossos modos de ser Kixelô!

\section{Problemáticas das (re)afirmações étnicas contemporâneas e garantias de direitos}

Embora os efeitos de políticas indigenistas assimilacionistas e integracionistas seculares são sentidos até os dias de hoje dentro e fora das nossas regiões algumas/uns intelectuais do nosso povo Quixelô como: Edileuza Santiago Nascimento Quixelô, Marileide Quixelô e Macedo Quixelô, estão produzindo estudos para não deixar que os nossos povos permaneçam nas invisibilidades. Enquanto continuarmos invisíveis para os diversos setores sociais, permaneceremos como um povo ET - (extraterrestre), ou seja, como inexistentes ou como estrangeiras/os em nossos próprios territórios ou fora deles. Assim como muito bem canta nossa querida parente Weena do povo Ticuna (AM/SP) em sua música: "500 anos iguais" (sou fã e recomendo). Por isso, são de grandes importâncias as pessoas se orgulharem e não terem vergonha (como acontece e é extremamente compreensível) das nossas origens.

As autoidentificações ou autodeclarações Quixelô é o primeiro passo para reconhecerem nossas (re)-existências e não ficarmos mais invisíveis ou "travestidas/os" em uma camisa de força (re)colonizadora "eurocentrada", ou seja, as direções que a dita civilização ocidental colonizadora tomou e ainda toma até os dias de hoje: desde a nossa mais 
tenra infância/educação nos "europeizar" (o que nem sempre funciona), ou nos mantendo nos setores empobrecidos populares como "exóticos do lado" (FONSECA, 2000) ao invés de deixar nos "indigenizar" ou nos "Quixelozear" como queira, ou com possibilidades de saber sobre as nossas origens nativas já nas infâncias para podermos fazer escolhas entre as duas ou mais culturas: indígenas/trans-brasileiras. Dessa forma, permanecem negando nossas (r)existências contemporâneas (sem educações indígenas diferenciadas) dentro do nosso território ou mesmo em contextos trans-localizados.

As autodeclarações são processos difíceis haja vista as retiradas seculares de nossas heranças ancestrais (NASCIMENTO QUIXELÔ, 2009, p.12) e suas permanências contemporâneas com as dificuldades de apoios em âmbitos institucionais locais e (trans)locais, além das possibilidades de escolhas entre-mundos advindas com as mestiçagens (SEGATO, 2012). Por isso, as autodeclarações podem ser também questões subjetivas (dentro e além-territórios); de "escolhas" já que para se autoidentificar as pessoas tem que estar esclarecidas/conscientes, estarem "seguras de si" e não temer os múltiplos preconceitos e opressões que enfrentamos (e enfrentaremos) ao nos orgulharmos de nossas raízes e origens. Para algumas pessoas, as autoidentificações não fazem diferença nenhuma e se contentam com "o que fizeram e fazem da gente". Para outras pessoas, porém, as autoconsciências são extremamente importantes e as autodeclarações são mais flexíveis já que ocupam posições sociais mais favoráveis que as possibilitam estudar, defender suas visões e projetar ações sem tantas barreiras. Outras ainda, não se autodeclaram por receio de perderem seus empregos ou espaços sociais (o que também acontece), por "ignorâncias de si" ou medo (e com razão) das muitas formas sutis ou escancaradas de negações/exclusões expressas de formas estruturais, sistêmicas e institucionais seculares ou de preconceitos, colonialismos ainda em curso (SEGATO, 2012) e violências extremadas vindas das diversas camadas e segmentos sociais em virtude das defesas dos nossos povos ou por conta das nossas (re)-existências contemporâneas.

\section{Alguns horizontes}

Pelo breve contexto histórico-antropológico do nosso povo Quixelô ancestral é possível perceber as dificuldades em torno de possíveis (re)afirmações étnicas contemporâneas principalmente para os povos indígenas do Nordeste haja vista que temos cerca de: 488 - (1500-1988) - de políticas indigenistas seculares: coloniais, imperiais, republicanas e ditatoriais; assimilacionistas, integracionistas e tutelares dos povos indígenas brasileiros. E para o nosso povo Quixelô (ancestral e contemporâneo) enfrentamos cerca de: 
318 anos (1700-2018) de (re)colonizações. Afetando assim, as nossas heranças culturais, linguísticas, territoriais, patrimoniais, reafirmações étnicas, etc. O período democrático abriu possibilidades de melhores condições de vida e de (r)-existências indígenas no planeta mesmo presenciando atualmente um congresso nacional brasileiro majoritariamente anti-indígena. Apesar disso, algumas legislações mais recentes reconhecerem as dívidas e formas de reparações históricas, as autonomias dos povos originários e os efeitos das (re)colonizações sobre as gerações contemporâneas e vindouras (ascendentes/mestiças nativas). A recente abertura política democrática (1985-2018) e com ela a Constituição Federal (1988-2018) trouxeram respectivamente: trinta e três anos de embrionária(s) democracia(s) e trinta anos de incipientes aberturas para se refletir sobre políticas públicas direcionadas as (r)-existências concretas de povos indígenas (ascendentes e mestiços) contemporâneos do/no Brasil com maiores protagonismos, intervenções, projeções e escutas das vozes indígenas.

A partir disso, podemos refletir sobre as dificuldades que assolam os povos originários do Nordeste inclusive o Ceará (dentre eles o nosso povo indígena/mestiço indígena Quixelô) e outros povos indígenas brasileiros em relação às diferentes dimensões de suas vidas: históricas, memoriais, patrimoniais, ambientais, artístico-culturais, territoriais, espirituaisreligiosas, medicinais, educacionais, linguísticas, simbólicas, epistemológicas (conhecimentos tradicionais), reafirmações pluriétnicas/mestiças, plurijurídicas/políticas, multi(est)éticas/corporais/sexuais/gêneros, (re)-existenciais, garantias de direitos e deveres nas duplas (ou múltiplas) cidadanias/ nacionalidades, (i)migrações locais e (trans)locais/globais, etc.

Grande parte dos povos indígenas brasileiros hoje são socializados em contextos coloniais urbanos (NASCIMENTO QUIXELÔ, 2009, p.269) e outra parte permanecem nas áreas tradicionais (IBGE, 2012) o que complexifica ainda mais as problemáticas em torno das elaborações de políticas públicas indígenas e indigenistas contemporâneas em relação às garantidas dos direitos e deveres em relação às duplas (ou múltiplas) cidadanias (indígenas/brasileiras/transnacionais) - dos mais de 305 povos nativos ainda (r)-existentes; dos outros tantos que estão por emergir (LUCIANO BANIWA, 2006, p.28) ou dos que ainda permanecem nas invisibilidades (NASCIMENTO, QUIXELÔ, 2009, p.280).

Nesse sentido, é possível pensar que as problemáticas e demandas indígenas não ficam reduzidas somente aos movimentos indígenas, mas são problemáticas a serem pensadas também por outros movimentos sociais: ambientalistas, feministas, LGBT`SIQs, sem terras (rurais) e tetos (urbanos); artísticos, negros, etc; por toda a sociedade brasileira e planetária 
haja vista que grande parte dos povos indígenas (e ascendentes) contemporâneos (con)vivem em meios urbanos/rurais nas cinco regiões brasileiras (Norte, Nordeste, Centro-Oeste, Sudeste e Sul) e além delas e fazem parte das sociedades ditas modernas coloniais e ocidentais, portanto, ocupam e contribuem com diferentes setores: sociais, religiosos, políticos e de movimentos sociais. O que os outros movimentos sociais têm haver e aprender com os movimentos indígenas? Tudo, um pouco mais e vice-versa!

Os movimentos e estudos pós-coloniais e de descolonizações contemporâneos refletem essas problemáticas não só nos territórios tradicionais (locais), mas também fora deles em contextos (trans)localizados. Pesquisadoras/es como: Santos (2007), Nascimento, Quixelô (2001; 2009), Segato (2012) dentre muitas/os outras/os vão nessas direções. As histórias e memórias dos povos indígenas brasileiros e de outros lugares do mundo estão interligadas com cronologias colonialistas e imperialistas comuns. Enfrentam problemas como: (i)migrações, imperialismos, colonialismos, usurpações/negações seculares, etc. Questões que fazem parte das histórias e memórias de muitos povos nativos brasileiros e merecem ser descortinadas rumo a outras direções que não as contadas (e constatadas) pela historiografia dita oficial (dos povos vencedores).

Por isso, muitos povos indígenas (e ascendentes) contemporâneas se apropriam das legislações indigenistas vigentes, de ferramentas tecnológicas virtuais, das artes / nativismos, das autodeclarações étnicas coletivas ou individuais, de outros movimentos sociais, etc, para assim garantir as continuidades das lutas indígenas ancestrais em perspectivas panindígenas/mestiças, multiétnicas/culturais e multidimensionais: locais, regionais, nacionais e globais. Podemos (re)pensar sobre nossas próprias histórias e memórias e tentar fazer não só os movimentos indígenas mas outros movimentos sociais (e também o planeta) refletir sobre as nossas muitas contemporaneidades, lugares concretos e reais nas reivindicações das duplas (nativas/brasileiras) ou múltiplas cidadanias (nacionalidades): 1) cidadanias indígenas/mestiças indígenas (mais de 305 povos pensando também os povos "emergentes" e invisibilizados); 2) cidadanias brasileiras (1 país, 26 estados, 1 distrito federal e cerca de 5570 municípios) e 3) cidadanias estrangeiras/planetárias (cerca de 200 países). Os povos indígenas (e ascendentes) circulam e migram em todas essas direções e regiões por isso suas demandas são pluriétnicas(híbridas), multiculturais e (trans)localizadas. As políticas que afetam as vidas dos povos originários (e ascendentes) estão relacionadas e interligadas as decisões tomadas não apenas em solos (locais) ancestrais ou pelas duplas perspectivas (indígenas/brasileiras), mas transbordam também por outras regiões com decisões de políticas estrangeiras (anteriores 
e atuais), além das políticas (trans)locais: regionais (municipais/estaduais), nacionais e globais que afetam suas vidas cotidianamente.

Nessas direções, podemos imaginar os gigantescos desafios que fazem partes dos movimentos indígenas e não-indígenas (com muitas presenças negadas dos nossos povos contemporâneos), no sentido de se contemplar todas essas dimensões, além das problemáticas sobrepostas por contextos históricos colonialistas seculares: tempo de contato que cada povo possui; impactos e efeitos das políticas indigenistas assimilacionistas/integracionistas nas gerações contemporâneas/vindouras- hoje com políticas diferenciadas em algumas regiões -, pluralidades étnicas (trans)regionalizadas, etc. Contextos esses, diferenciados para cada povo aumentando os desafios a serem enfrentados dentro ou fora de seus territórios. Assim como assistimos as modernizações das legislações trabalhistas e outras (com todas as suas problemáticas e lacunas); indígenas/mestiças/os, pesquisadoras/es, agentes estatais e formuladoras/es das legislações indigenistas contemporâneas também precisam atualizar/acompanhar as dinâmicas pluriétnicas, interétnicas e multi/interculturais (de modernizações ou não) que cada povo indígena enfrente ou deseja pensando os diferentes povos originários que compõem as pluralidades étnicas brasileiras (onde esses têm hoje ao menos possibilidades e legislações que asseguram se irão passar por mudanças com decisões advindas de suas próprias escolhas ou não), ou seja, com consultas prévias e participações efetivas dos povos nas formulações de políticas públicas que os afetam em seus cotidianos. Temos exemplos da Bolívia que já avançou bastante nas representatividades pluriétnicas democráticas (todos os povos indígenas do país) sendo representados inclusive no espaço mais importante nas tomadas de decisões: o congresso nacional boliviano.

Esses contextos nos fazem refletir também sobre como as políticas indigenistas durante muitos séculos encobriram (e ainda encobrem) as muitas históricas e memórias brasileiras (pensando aqui sempre no plural, pois são muitos os povos indígenas, portanto muitos os movimentos e histórias nativas brasileiras a serem (re)pensadas); sempre tiveram um caráter impositivo (quase nunca sendo escolhas dos povos indígenas decidirem aderir ou não as inserções às ditas sociedades ocidentais coloniais), além das muitas outras problemáticas advindas com as "integrações forçadas" ou caráter tutelar de políticas indigenistas governamentais sem consultar os povos sobre políticas que os afetam ou sem ouvir suas escolhas e os impactos nas suas vidas.

Com essas pequenas contribuições, não pretendemos dar conta das tantas complexidades que afetam e envolvem os nossos povos originários (ancestrais e atuais) nas 
contemporaneidades, mas podemos buscar entender os passados, refletir os presentes e projetar outros futuros para os diferentes povos indígenas não só do Nordeste; do Ceará (inclusive o povo Quixelô), mas também para os povos nativos de outras regiões brasileiras, além de outros povos originários do mundo que também fazem parte dessas imensas diversidades étnicas que compõem o(s) Brasil(is) para que possam enfrentar problemáticas referentes às indigenidades/mesticidades (cidadãs nativas/brasileiras/transnacionais), prematuras ou tardias a serem (re)pensadas, formuladas e aplicadas com as participações dos povos originários em suas multidimensionais formas de lutas coletivas ou individuais em contextos (trans)localizados; pelos muitos movimentos indígenas e não-indígenas brasileiros ou estrangeiros (pensando inclusive as presenças híbridas/mestiças nativas negadas).

Questões a serem descortinadas/contempladas também em relação às memórias e histórias seculares dos povos indígenas (e ascendentes) como são e estão nas contemporaneidades e não apenas como ainda alimentam muitos imaginários sociais que infelizmente fazem parte das formações educacionais iniciais até universitárias de muitas/os brasileiras/os. Desembocando inclusive em "indigenidades tardias” (QUIXELÔ, 2015, p. 27) para pessoas ascendentes e mestiças dos povos nativos (SEGATO, 2012, p.115) que crescem e vivem em contextos coloniais (trans)locais urbanos ou rurais.

Esses imaginários esbarram nas complexidades e desinformações sobre as complicadas realidades concretas pelas quais passam muitos povos secularmente negados/apagados, nas garantias dos seus direitos (e deveres) com base nas legislações indigenistas vigentes e nas formulações de políticas públicas indígenas e indigenistas contemporâneas mais condizentes com essas realidades. Afetam as vidas de ascendentes nativos que tem possibilidades hoje (ao menos com leis vigentes mesmo que não praticadas), de poderem ser ouvidas/os em suas escolhas; de participarem ou não nas decisões sobre os melhores caminhos para se assegurar suas (r)-existências e bem-viveres indígenas (e/ou híbridos) no planeta; seja nos modelos tradicionais ou modernos coloniais, ou contemplando os dois (ou mais) ao mesmo tempo, dentro também de realidades mais democráticas (nativas/brasileiras/estrangeiras/híbridas) pluriétnicas, multiculturais e multidimensionais locais e (trans)locais/globais.

\section{Referências}

ANTUNES, Ticiana. 1863: o ano em que um decreto - que nunca existiu - extinguiu uma população indígena que nunca deixou de existir. Aedos, n.10, vol. 4, p.8-27, Jan/Jun, 2012 (disponível) 
CONSELHO Indigenista Missionário (CIMI). Outros 500: construindo uma nova história. São Paulo: Editora Salesiana, 2001

FONSECA, Claudia. Família, fofoca e honra: etnografia das relações de gênero e violência em grupos populares. Porto Alegre: Editora da UFRGS, 2000

GARCIA, Elisa Fhurauf. O projeto pombalino de imposição da língua portuguesa aos índios e a sua aplicação na América Meridional. Tempo, Dossiê, p. 23-38, Abr/Mai, 2007 (disponível)

LUCIANO, Gersem. (Baniwa). O índio brasileiro: o que você precisa saber sobre os povos indígenas brasileiros hoje. Brasília: UNESCO, 2006 (disponível)

MACEDO, Adail Alves. (Quixelô). Culturas, identidades e territórios: a cultura e a identidade indígena Kixelô. Quixelô-CE: UFCA-PROCULT, 2016

MARTINS, Fabio E. S. As sociedades indígenas e a comissão nacional da verdade. Revista Moitará. Araraquara-SP, vol. 2, n. 1, p. 18-26. Nov-Dez, 2014 (disponível)

MINISTÉRIO DO PLANEJAMENTO. IBGE. Censo Demográfico 2010 - Características gerais indígenas: resultado do universo. Rio de Janeiro, 2012 (disponível)

NASCIMENTO, Edileuda Santiago. (Quixelô). O Sertão Indígena na Região Centro-Sul e os Kixelô de Quixelô. Iguatu-CE: Jornal Centro-Sul, 2015.

NASCIMENTO, Edileusa Santiago do. (Quixelô) Memória coletiva e identidade étnica dos Tremembé de Almofala: os índios da terra da santa de ouro. Dissertação de Mestrado em Psicologia Social na Universidade Federal de Minas Gerais. Belo Horizonte, 2001 (disponível)

(Quixelô). Identidade e memória de habitantes de Fortaleza-CE originários da comunidade Tremembé de Almofala-CE: ramas de raízes indígenas em trânsito na cidade. PUC: São Paulo, 2009 (disponível)

NIMUENDAJU, Curt. Mapa-etnohistórico do Brasil e regiões adjacentes. Fundação Nacional Pró-Memória. IBGE. Rio de Janeiro: 1981 (disponível)

OLIVEIRA, João Pacheco de. Uma etnologia dos "índios misturados"? Situação colonial, territorialização e fluxos culturais. Mana. Rio de Janeiro - UFRJ, vol 4, n. 1, p.47-77. Abr, 1998. (disponível)

A viagem da Volta: etnicidade, política e reelaboração cultural no nordeste indígena. (Org.) Rio de Janeiro: Contra Capa, 1999.

RABESCO, Rafaela. O ensino de história e cultura indígena na escola: os desafios da formação e da prática educativa através da musicalização. Revista Moitará. Araraquara- SP, vol 2, n. 1, p. 46-55. Nov-dez, 2014 (disponível)

SEGATO, Rita Laura. Gênero e colonialidade: em busca de chaves de leitura e de um vocabulário estratégico descolonial. Epistemologias feministas: ao encontro da crítica radical. e-cadernos CES [Online], 18 | 2012, p. 106-131 (disponível)

SANTOS, Boaventura de Sousa, 1940- Renovar a teoria critica e reinventar a emancipação social / Boaventura de Sousa Santos; tradução Mouzar Benedito. - São Paulo: Boitempo, 2007 (disponível)

QUIXELÔ, Marleide. (Quixelô). Façamos das nossas (r)existências indígenas cotidianas atuais as muitas resistências indígenas ancestrais. In: Memórias do Movimento Indígena do Nordeste. , Gabriela Saraiva de e Sebastián Gerlic. (orgs MELLO). Ilhéus - BA: Coleção Índios na visão dos índios, 2015, p. 26- 27. (disponível) 


\section{Sites consultados}

https://al.ce.gov.br/index.php/ultimas-noticias/item/4638-1405rt-audiencia-rachel http://www.renatoroseno.com.br/noticias/dia-do-indio-falta-de-demarcacao-de-terras-causaviolencia-e-violacao-de-direitos-indigenas

Legislações pós-Constituição Federal BRASIL. Constituição (1988). Constituição da República Federativa do Brasil. Brasília, DF: Senado, 1988. (disponível)

BRASIL. Ministério da Educação e Cultura. Secretaria de Educação Fundamental. Parâmetros Curriculares Nacionais: pluralidade cultural, orientação sexual. Brasília: MEC/SEF, 1997 (disponível)

Convenção $n^{\circ} 169$ sobre povos indígenas e tribais e Resolução referente à ação da OIT / Organização Internacional do Trabalho (2004). - Brasília: OIT, 2011 (disponível)

Declaração das Nações Unidas sobre os Direitos dos Povos Indígenas, 2007 (disponível) BRASIL. PRESIDÊNCIA DA REPÚBLICA. CASA CIVIL. SUBCHEFIA PARA ASSUNTOS JURÍDICOS. Lei $n^{\circ} 11.645$, de 10 de março de 2008. Altera a Lei no 9.394, de 20 de dezembro de 1996, modificada pela Lei no 10.639, de 9 de janeiro de 2003, que estabelece as diretrizes e bases da educação nacional, para incluir no currículo oficial da rede de ensino a obrigatoriedade da temática "História e Cultura Afro-Brasileira e Indígena". (disponível)

Silva, Luiz Fernando Villares e. (Org.). Coletânea da legislação indigenista brasileira. Brasília: CGDTI/FUNAI, 2008 (disponível) 